\title{
The Preparation and Performance Study of a Phosphate-Free Corrosion/Scale Inhibitor
}

\author{
Defang Zeng*, Wei Zhang \\ School of Resource and Environmental Engineering, Wuhan University of Technology, Wuhan, China \\ Email: *xj1987@yahoo.cn
}

Received November 29, 2011; revised April 3, 2012; accepted May 7, 2012

\begin{abstract}
By using acrylic acid copolymer, sodium citrate, hydrolyzed polymaleic anhydride (HPMA), corrosion inhibitor D and $\mathrm{Zn}^{2+}$ synergist as raw materials, a multi-component phosphate-free corrosion and scale inhibitor was developed. The performance of the composite phosphate-free corrosion and scale inhibitor was evaluated using the rotary hanging sheet corrosion test, the static scale inhibition test and the corrosion electrochemical test. And the surface morphology of the carbon steel was observed by scanning electronic microscope (SEM). Orthogonal experiment results indicated that the optimal mass ratios of amino acid: $\mathrm{Zn}^{2+}$ synergist: HPMA: corrosion inhibitor D: acrylic acid copolymer was $0.5: 10: 12: 1: 8$. It was also observed that phosphate-free corrosion and scale inhibitor based on an anodic reaction through the electrochemical corrosion experiment, its annual corrosion rate and scale inhibition rate reached 0.0176 $\mathrm{mm} \cdot \mathrm{a}^{-1}$ and $98.3 \%$, respectively, showing excellent corrosion and scale inhibition performance.
\end{abstract}

Keywords: Phosphate-Free Corrosion/Scale Inhibitor; Static Scale Inhibition Method; SEM; Electrochemical Corrosion

\section{Introduction}

Industrial recirculating cooling water accounts for $60 \%$ $70 \%$ in the industrial water, it will result in corrosion, scaling and microbial slime of the equipment and the pipeline as well as reduce their service life without treating. Thus, to treat recirculating cooling water has aroused the concern from the whole society.

Organophosphorus compound was a type of corrosion inhibitor extensively used since 1980s. However, it's diminishing because of its toxic effects on aquatic and other life [1]. Therefore, the public began to focus on the development of low phosphorus, non-phosphorus and heavy nonmetal salt corrosion and scale inhibitors. On one hand, low phosphorus corrosion and scale inhibitor is developing rapidly, such as 2-phosphono-1,2,4-tricarboxylic acid butane (PBTCA) and hydrolyzed polymaleic anhydride (HPMA) [2]. On the other hand, the non-phosphorus corrosion and scale inhibitor has also obtained new achievements.

In this paper, a multi-component phosphate-free corrosion and scale inhibitor blend composed of acrylic acid copolymer, sodium citrate, hydrolyzed polymaleic anhydride (HPMA), corrosion inhibitor $\mathrm{D}$ and $\mathrm{Zn}^{2+}$ synergist was prepared [3-7]. The recirculating cooling water was obtained from water treatment plant. The performance of the phosphate-free corrosion and scale inhibitor was eva-

\footnotetext{
${ }^{*}$ Corresponding author.
}

luated by rotary hanging sheet corrosion test and static scale inhibition test. The mechanism of corrosion and scale inhibition was preliminarily investigated by corrosion electrochemistry test and scanning electron microscope (SEM) techniques [8-11].

\section{Experimental}

\subsection{Main Materials}

Acrylic acid copolymer, sodium citrate, hydrolyzed polymaleic anhydride (HPMA), sodium citrate, $\mathrm{Zn}^{2+}$ synergist and anhydrous alcohol. All chemicals were of analytical reagent-grade.

\subsection{The Rotary Hanging Sheet Corrosion Test}

The corrosion rate of A3 type carbon steel was determined by weight loss test. The carbon steel sheets were polished with different grades of emery paper, degreased with anhydrous alcohol, and rinsed with distilled water. Having been dried by electric dry oven and accurately weighed by electronic balance, the carbon steel were immersed in a beaker with water sample and with or without inhibitors. And the quality index of water sample was presented in Table 1. The beakers were put into the rotary hanging piece corrosion test instrument. Experimental conditions as follows: 1) constant temperature was $45^{\circ} \mathrm{C} \pm 1{ }^{\circ} \mathrm{C}$; 2) rotating speed was $75 \mathrm{r} \cdot \mathrm{min}^{-1}$; 3) 
Table 1. Water quality index.

\begin{tabular}{cc}
\hline Project & Analysis value \\
\hline $\mathrm{pH}$ value & 7.24 \\
calcium ion $/\left(\mathrm{mg} \cdot \mathrm{L}^{-1}\right)$ & 92.57 \\
magnesium ion $/\left(\mathrm{mg} \cdot \mathrm{L}^{-1}\right)$ & 61.28 \\
chloride ion $/\left(\mathrm{mg} \cdot \mathrm{L}^{-1}\right)$ & 397.5 \\
total hardness $/\left(\mathrm{mmol} \cdot \mathrm{L}^{-1}\right)$ & 4.54 \\
total alkalinity $/\left(\mathrm{mmol} \cdot \mathrm{L}^{-1}\right)$ & 4.37 \\
potassium ion $/\left(\mathrm{mg} \cdot \mathrm{L}^{-1}\right)$ & 15.24 \\
conductivity $/(\mu \mathrm{s} \cdot \mathrm{cm}$ & $-1)$ \\
total dissolved solids content $/\left(\mathrm{mg} \cdot \mathrm{L}^{-1}\right)$ & 925 \\
\hline
\end{tabular}

experimental period was 72 hours. After 72 hours, the carbon steel sheets were taken out, washed, dried and accurately weighed. Each set of experiments was repeated three times at least to ensure reproducibility. According to Technical Conditions of Standard Corrosion Spool of Chemical Treatment in Cooling Water (HG/ T3523-2008), A3 type carbon steel with a size of $50 \mathrm{~mm}$ $\times 25 \mathrm{~mm} \times 2 \mathrm{~mm}$ and an area of $28 \mathrm{~cm}^{2}$ in the experiment.

The annual corrosion rate and corrosion inhibition efficiency was calculated by formulae (1) and (2), respectively [12]:

$$
K_{a}=\frac{87600\left(m_{0}-m\right)}{s \rho t}
$$

where $K_{a}$ is the annual corrosion rate, $\mathrm{mm} \cdot \mathrm{a}^{-1} ; m_{0}$ is the weight of the carbon steel before experiment, $g$; $m$ is the weight of the carbon steel after experiment, g; $s$ is the surface area of the carbon steel, $\mathrm{cm}^{2} ; \rho$ is the density of the carbon steel, $\mathrm{g} \cdot \mathrm{cm}^{-3} ; t$ is the test time, $\mathrm{h}$.

$$
K=\frac{\left(K_{0}-K_{1}\right)}{K_{0}} \times 100 \%
$$

where $K$ is the corrosion inhibition efficiency; $K_{0}$ and $K_{1}$ are the values of the weight loss of carbon steel after being immersed in solutions without and with inhibitors, respectively, $\mathrm{mm} \cdot \mathrm{a}^{-1}$.

\subsection{The Static Scale Inhibition Test}

The mechanism of scaling inhibition mainly included lattice deformation, complexation, dispersion effect and dispersive active $[13,14]$. In the experiment, $0.5 \mathrm{~L} \cdot \mathrm{min}^{-1}$ of nitrogen was ventilated to the bottom of the container with adding $30 \mathrm{mg} \cdot \mathrm{L}^{-1}$ of inhibitor at $45^{\circ} \mathrm{C}$. The experiment was ceased after six times diluted concentration.

$$
\eta_{K}=\frac{C_{2}-C_{1}}{K \times C_{0}-C_{1}} \times 100 \%
$$

where $C_{2}$ is determined mass concentration of calcium ion after adding chemicals, $\mathrm{mg} \cdot \mathrm{L}^{-1} ; C_{1}$ is determined mass concentration of calcium ion without chemicals, $\mathrm{mg} \cdot \mathrm{L}^{-1} ; C_{0}$ is initial mass concentration of calcium ion without chemicals, $\mathrm{mg} \cdot \mathrm{L}^{-1} ; K$ is the concentration multiple in the determined conditions of $C_{2}$ and $C_{1}$.

\section{4 .Corrosion Electrochemical Experiments}

Corrosion electrochemical methods consulted the research methods and measurement techniques in other fields. According to the characteristics and requirements of corrosion metal electrodes, it has become a significant method for the research and measurement of corrosive electrochemistry with improvement and modification. In particular, the dynamic potential polarization is the common method that evaluates inhibition efficiency of corrosion inhibitor [15]. Polarization curve obtained from the dynamic potential polarization extrapolates corrosion potential to obtain corrosion current density I and Tafel parameters. The shape of cathode and anodic polarization curve intuitively reflects the corrosion inhibition mechanism of corrosion inhibitors, which is the main research and evaluation method of corrosion inhibitors.

Electrodes were connected by three electrodes polarization method in the experiment. A3 carbon steel was used as the working electrode, saturated calomel electrode (SCE) as the reference electrode and platinum sheet as the auxiliary electrode. The sample was immersed in a $3.5 \%(\mathrm{w} / \mathrm{w}) \mathrm{NaCl}$ solution for $30 \mathrm{~min}$. When polarization curve test was carried out, the potential scan rate was adjusted to $0.01 \mathrm{v} \cdot \mathrm{s}^{-1}$. Polarization curves could be achieved after data process.

\subsection{Scanning Electronic Microscopy (SEM)}

Corrosion crystal morphology on the surface of A3 carbon steel was observed by JSM5610LV type SEM. In this experiment, A3 carbon steel was immersed in water sample with and without phosphate-free scale and corrosion inhibitor, respectively. Afterwards the test coupon was washed with $98 \%$ (w/w) anhydrous alcohol and treated for vacuum drying. Accelerating voltage of the JSM5610LV type SEM was $25 \mathrm{kV}$, amplification factor was 2000 .

\section{Results and Discussion}

\subsection{Rotating Hang-Parcel Weight-Loss Experimental Performance Analysis}

The inhibitor in this experiment composed of $\mathrm{A}$ (sodium citrate), B ( $\mathrm{Zn}^{2+}$ synergist), C (HPMA), corrosion inhibitor D and E (acrylic copolymer). L16 (4 $\left.4^{5}\right)$ orthogonal table was used to arrange experiment.Corrosion rate of the carbon steel was determined after 72 hours, the final result was the average values of three replicates. The re- 
sults were showed in Table 2.

As shown in Table 2, the sequence of the influencing factors was corrosion inhibitor $\mathrm{D}>$ Amino acid $>\mathrm{Zn}^{2+}$ synergist $>$ acrylic copolymer $>$ HPMA in order of importance to the corrosion rate. According to orthogonal experiment results, the optimum formula was $\mathrm{D}_{4} \mathrm{~A}_{4} \mathrm{~B}_{4} \mathrm{E}_{1} \mathrm{C}_{1}$ on corrosion inhibition. Based on the optimum formula, the weight loss experiment was carried out. The mass ratios of amino acid, $\mathrm{Zn}^{2+}$ synergist, HPMA, corrosion inhibitor $\mathrm{D}$ and acrylic copolymer was $0.5: 12: 0: 1: 8$ in the optimum formula. The results were presented in Table 3.

The corrosion inhibition efficiency of optimized formulation reached 96.6\% (Table 3), showing good corro- sion inhibition effect.

\subsection{Static Scale Inhibition Performance Analysis}

Comparison experiments were conducted with and without inhibitors. The relationship between the concentration of $\mathrm{Ca}^{2+}, \mathrm{HCO}_{3}^{-}$and cycle of concentration was showed in Figure 1.

When the solution concentration was concentrated by 1 - 1.8 times, the concentration of $\mathrm{Ca}^{2+}$ and $\mathrm{HCO}_{3}^{-}$ showed linear change, illustrating that $\mathrm{Ca}^{2+}$ and $\mathrm{HCO}_{3}^{-}$ were unsaturated in solution. The concentration of $\mathrm{HCO}_{3}^{-}$appeared increases linearly with the inhibitor,

Table 2. Design of orthogonal experiment L16 $\left(4^{5}\right)$ and experiment results.

\begin{tabular}{|c|c|c|c|c|c|c|}
\hline \multirow[b]{2}{*}{ Numbers } & \multicolumn{5}{|c|}{ Experimental factor } & \multirow[b]{2}{*}{$\begin{array}{l}\text { Average corrosion } \\
\text { rate } / \mathrm{mm} \cdot \mathrm{a}^{-1}\end{array}$} \\
\hline & $\begin{array}{c}\text { A } \\
\text { Amino acid } \\
/ \mathrm{mg} \cdot \mathrm{L}^{-1}\end{array}$ & $\begin{array}{c}\mathrm{B} \\
\mathrm{Zn}^{2+} \text { synergist/ } \\
\mathrm{mg} \cdot \mathrm{L}^{-1}\end{array}$ & $\begin{array}{c}\mathrm{C} \\
\mathrm{HPMA} / \mathrm{mg} \cdot \mathrm{L}^{-1}\end{array}$ & $\begin{array}{c}\mathrm{D} \\
\text { Corrosion inhibitor/ } \\
\mathrm{mg} \cdot \mathrm{L}^{-1}\end{array}$ & $\begin{array}{c}\mathrm{E} \\
\text { Acrylic copolymer/ } \\
\mathrm{mg} \cdot \mathrm{L}^{-1}\end{array}$ & \\
\hline 1 & 0.3 & 9 & 10 & 0.8 & 5 & 0.0245 \\
\hline 2 & 0.3 & 10 & 11 & 0.9 & 8 & 0.0225 \\
\hline 3 & 0.3 & 11 & 12 & 1 & 7 & 0.0239 \\
\hline 4 & 0.3 & 12 & 13 & 1.1 & 6 & 0.0214 \\
\hline 5 & 0.4 & 9 & 11 & 1 & 8 & 0.0221 \\
\hline 6 & 0.4 & 10 & 10 & 1.1 & 7 & 0.0260 \\
\hline 7 & 0.4 & 11 & 13 & 0.8 & 6 & 0.0299 \\
\hline 8 & 0.4 & 12 & 12 & 0.9 & 5 & 0.0230 \\
\hline 9 & 0.5 & 9 & 12 & 1.1 & 6 & 0.0234 \\
\hline 11 & 0.5 & 11 & 10 & 0.9 & 8 & 0.0288 \\
\hline 12 & 0.5 & 12 & 11 & 0.8 & 7 & 0.0310 \\
\hline 13 & 0.6 & 9 & 13 & 0.9 & 7 & 0.0211 \\
\hline 14 & 0.6 & 10 & 12 & 0.8 & 8 & 0.0205 \\
\hline 15 & 0.6 & 11 & 11 & 1.1 & 5 & 0.0197 \\
\hline 16 & 0.6 & 12 & 10 & 1 & 6 & 0.0271 \\
\hline 17 & 0 & 0 & 0 & 0 & 0 & 0.5215 \\
\hline $\mathrm{i} / 5$ & 0.1064 & 0.1059 & 0.0921 & 0.0923 & 0.0901 & \\
\hline $\mathrm{ii} / 5$ & 0.0953 & 0.0954 & 0.0919 & 0.1010 & 0.1029 & \\
\hline $\mathrm{iii} / 5$ & 0.0908 & 0.0960 & 0.1023 & 0.1061 & 0.1010 & \\
\hline iv/5 & 0.0943 & 0.0905 & 0.0926 & 0.0884 & 0.0918 & \\
\hline
\end{tabular}

Table 3. Optimizing formula experimental results.

\begin{tabular}{|c|c|c|c|c|c|c|}
\hline Experiment & $\begin{array}{c}\text { Hang-parcel } \\
\text { number }\end{array}$ & $\begin{array}{l}\text { Quality of hang-parcel } \\
\text { before experiment/g }\end{array}$ & $\begin{array}{l}\text { Quality of hang-parcel } \\
\text { after experiment/g }\end{array}$ & $\begin{array}{l}\text { Weight } \\
\text { loss/g }\end{array}$ & $\begin{array}{l}\text { Annual corrosion rate } \\
\qquad / \mathrm{mm} \cdot \mathrm{a}^{-1}\end{array}$ & $\begin{array}{c}\text { Inhibition } \\
\text { efficiency } / \%\end{array}$ \\
\hline \multirow{3}{*}{$\begin{array}{l}\text { Optimized } \\
\text { formulation }\end{array}$} & 1152 & 19.2498 & 19.2465 & 0.0033 & & \multirow{6}{*}{96.6} \\
\hline & 1153 & 19.1601 & 19.1567 & 0.0034 & 0.0176 & \\
\hline & 1154 & 19.0684 & 19.0655 & 0.0029 & & \\
\hline \multirow{3}{*}{ Blank } & 1155 & 19.8299 & 19.7576 & 0.0945 & \multirow{3}{*}{0.5208} & \\
\hline & 1156 & 19.2922 & 19.2204 & 0.0940 & & \\
\hline & 1115 & 19.3625 & 19.2941 & 0.0938 & & \\
\hline
\end{tabular}




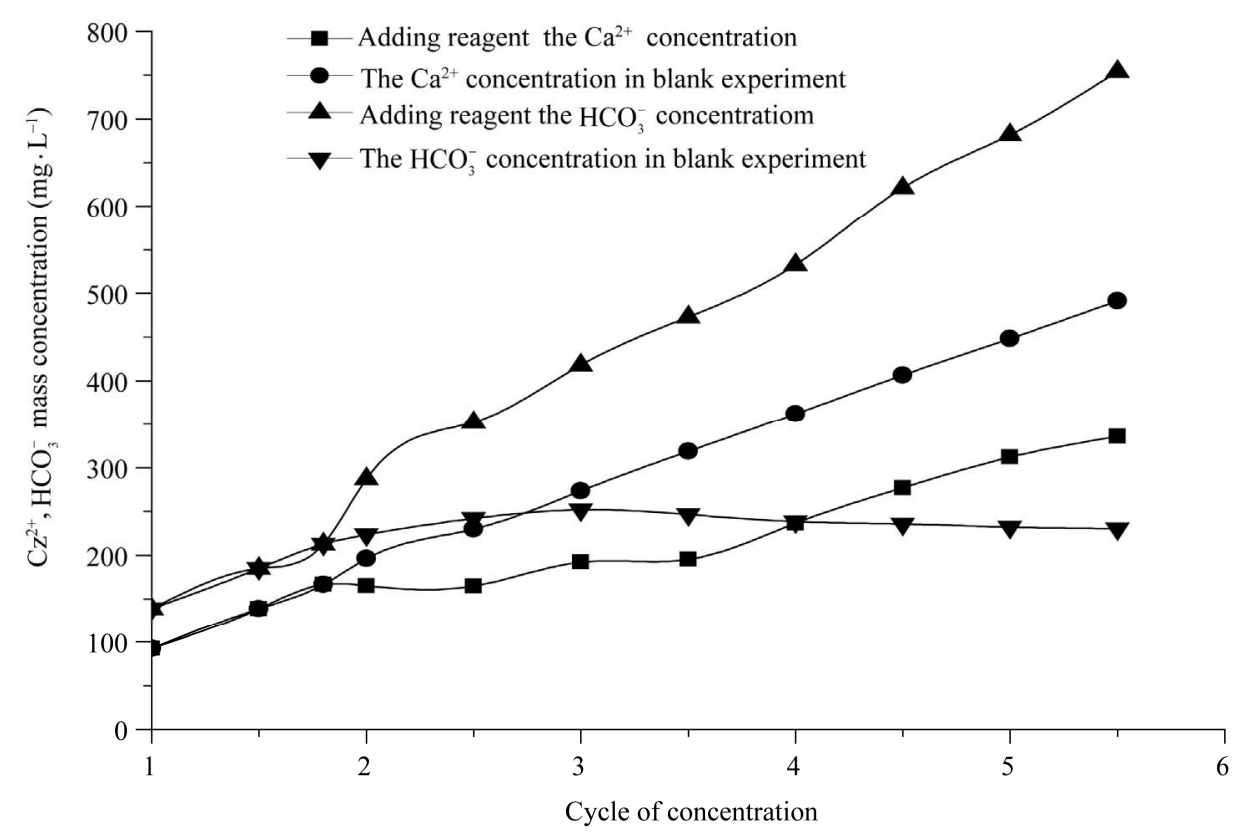

Figure 1. $\mathrm{Ca}^{2+}, \mathrm{HCO}_{3}^{-}$concentration and concentration multiple relationship chart.

while it increased slowly and even tended to decrease without the inhibitor. And the concentration of $\mathrm{Ca}^{2+}$ basically showed increases linearly with and without inhibitor, respectively. Experimental results showed that the concentrations of $\mathrm{Ca}^{2+}$ and $\mathrm{HCO}_{3}^{-}$in the solution were stabilized after adding inhibitor.

According to the results of Table 4, the average scale inhibition efficiency with phosphate-free corrosion and scale inhibitor reached $98.3 \%$, showing good scale inhibition performance.

\subsection{Corrosion Electrochemistry Results Analysis}

Two specimens were immersed in $3.5 \% \mathrm{NaCl}$ solution with and without inhibitor, respectively. Then the test method of electrochemical polarization curve was conducted. The results were presented in Table 5 and Figure 2. And the inhibition efficiency of the inhibitor for the carbon steel corrosion was calculated by formula (4):

$$
\eta=\frac{I_{\text {corr }}-I_{\text {corr }}^{\prime}}{I_{\text {corr }}} \times 100 \%
$$

In Figure 2, the corrosion potential was shift to the positive after adding the inhibitor. The increasing in anodic current density indicated that the dissolution of the anode materials. Figure 2 showed the anode $I_{\text {corr }}$ was reduced from $201 \mu \mathrm{A} \cdot \mathrm{cm}^{2}$ to $21 \mu \mathrm{A} \cdot \mathrm{cm}^{2}$ after adding the inhibitor. It indicated that the anode corrosion process was inhibited. And the anode inhibition was more significantly than the cathode with the inhibitor. Table 3 and Table 5 showed the consistent results with electrochemical test.

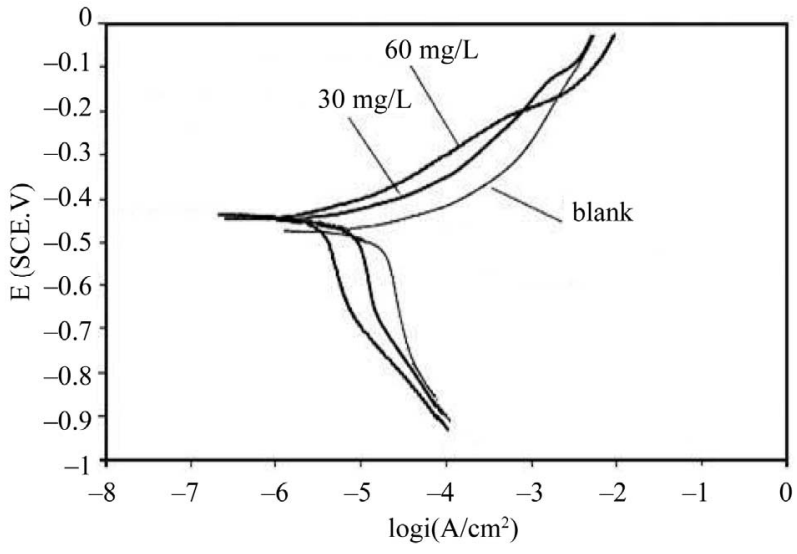

Figure 2. The polarization curve of blank and adding phosphate-free scale corrosion inhibitor treated samples in $3.5 \% \mathrm{NaCl}$ solution.

\subsection{SEM Structure Analysis}

The experimental conditions as followed: the bath temperature was maintained at $50^{\circ} \mathrm{C}$ for $48 \mathrm{~h}$, the flow rate of solution and the cycle of concentration were adjusted to $0.01 \mathrm{~m} \cdot \mathrm{s}^{-1}$ and 1.8 times, respectively. The concentration of phosphate-free corrosion and scale inhibitor was 30 $\mathrm{mg} \cdot \mathrm{L}^{-1}$. Figures 3(a) and (b) were corrosion crystal on A3 carton steel surface with and without phosphate-free corrosion and scale inhibitor, respectively.

Figure 3 showed that the carbon steel was corroded severely without the inhibitor, many apertures appeared on its surface and some corrosion products deposited on the surface with uplift shape. In comparison, the surface of the carbon steel with $30 \mathrm{mg} \cdot \mathrm{L}^{-1}$ of phosphate-free 
Table 4. Scale inhibition efficiency with different concentration multiple.

\begin{tabular}{ccccc}
\hline $\begin{array}{c}\text { Concentration } \\
\text { multiple/K }\end{array}$ & $\begin{array}{c}\text { Theoretical value } \\
\mathrm{Ca}^{2+} /\left(\mathrm{mg} \cdot \mathrm{L}^{-1}\right)\end{array}$ & $\begin{array}{c}\text { Without chemicals } \\
\mathrm{Ca}^{2+} /\left(\mathrm{mg} \cdot \mathrm{L}^{-1}\right)\end{array}$ & $\begin{array}{c}\text { Adding chemicals } \\
\mathrm{Ca}^{2+} /\left(\mathrm{mg} \cdot \mathrm{L}^{-1}\right)\end{array}$ & $\begin{array}{c}\text { Scale inhibition efficiency } \\
\eta_{\mathrm{k}} / \%\end{array}$ \\
\hline 2.5 & 231.4 & 166.7 & 230.8 & 99.1 \\
3 & 277.7 & 180.1 & 271.0 & 98.2 \\
3.5 & 324.0 & 195.2 & 320.6 & 98.5 \\
4 & 370.1 & 236.7 & 368.1 & 98.3 \\
4.5 & 416.5 & 270.1 & 415.1 & 98.7 \\
5 & 462.8 & 308.2 & 460.2 & 99.1 \\
5.5 & 509.1 & 330.2 & 504.2 & 98.0 \\
Average & & & & 98.3 \\
\hline
\end{tabular}

Table 5. Electrochemical parameter with different concentrations of corrosion inhibitor in $3.5 \% \mathrm{NaCl}$ solution.

\begin{tabular}{cccc}
\hline Concentration of corrosion inhibitor $/ \mathrm{mg} \cdot \mathrm{L}^{-1}$ & $E_{\text {corr }}(\mathrm{vsSCE}) / \mathrm{mV}$ & $I_{\text {corr }} / \mu \mathrm{A} \cdot \mathrm{cm}^{2}$ & 201 \\
\hline 0 & -482 & -443 & 21 \\
30 & -435 & 19 & 90.56 \\
\hline
\end{tabular}

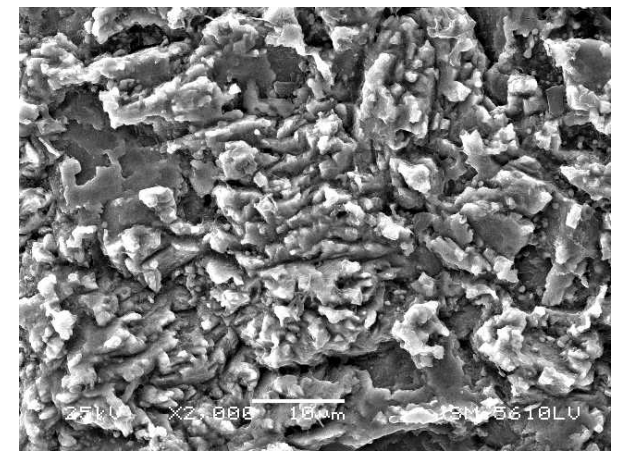

(a)

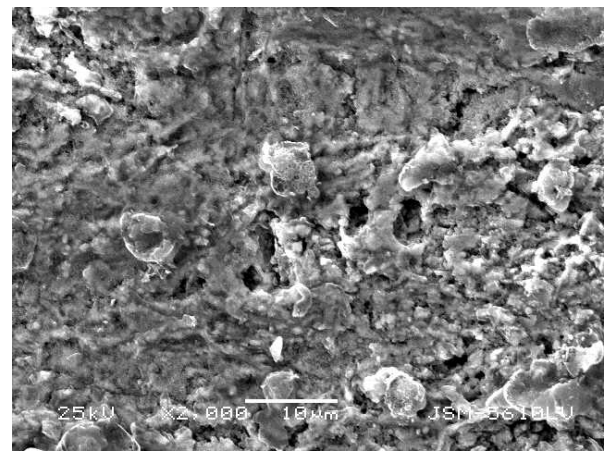

(b)

Figure 3. The corrosion crystal on A3 carton steel surface.

corrosion and scale inhibitor was flat and smooth. It caused some damage and few corrosion products accumulation on the surface of the carbon steel because of polishing hang-parcel. But there were basically no corrosion marks. Results illustrated that a complete compact protective film formed on carbon steel surface after adding phosphate-free corrosion and scale inhibitor. It effectively cut off contact between the corrosive medium and carbon steel surface so as to significantly inhibit the corrosion of carbon steel in water sample.

\section{Conclusions}

1) A phosphate-free corrosion and scale inhibitor composed of A (sodium citrate), $\mathrm{B}$ ( $\mathrm{Zn}^{2+}$ synergist), $\mathrm{C}$ (HPMA), corrosion inhibitor D and E (acrylic copolymer). The optimized mass ratio of amino acid: $\mathrm{Zn}^{2+}$ synergist: HPMA: corrosion inhibitor D: acrylic acid copolymer was $0.5: 10: 12: 1: 8$.

2) Annual corrosion rate tested by optimized rotating hang-parcel corrosion experiment was $0.0176 \mathrm{~mm} \cdot \mathrm{a}^{-1}$ which was lower than $0.075 \mathrm{~mm} \cdot \mathrm{a}^{-1}$ of industry standard according to Code for Design of Industrial Recirculating Cooling Water Treatment (GB50050-2007). The experimental results showed that the phosphate-free corrosion and scale inhibitor was a kind of good corrosion and scale inhibitor whose corrosion inhibition rate and scale inhibition rate surpassed $96 \%$ and $98 \%$, respectively.

3) Polarization curve test showed the phosphate-free corrosion and scale inhibitor was a kind of corrosion and scale inhibitor that mainly caused anode type reaction. Based on the surface morphology of the carbon steel was observed by SEM, it showed that a protective film was formed on the surface of A3 carbon steel with optimized phosphate-free corrosion and scale inhibitor.

\section{Acknowledgements}

The authors gratefully acknowledge School of Resource and Environmental Engineering, Wuhan University of 
Technology institute of the facilities and test environments. We also thank the Science and Technology Department of Hubei (China) to provide financial support.

\section{REFERENCES}

[1] D. Darling and R. Rakshpa, "Green Chemistry Applied to Corrosion and Scaleinhibitore," Journal of Chemical Treatment, Vol. 23, No. 9, 1998, pp. 42-45.

[2] Z.-M. Wang and L.-K. Cai, "The Study of Organic Phosphoric Acidtype Water Stabilizer," Journal of East China Institute of Chemical Technology, Vol. 14, No. 5, 1898, pp. 603-608.

[3] M. A. Quraishi, A. Singh and V. Kumar Singh, "Green Approach to Corrosion Inhibition of Mild Steel in Hydrochloric Acid and Sulphuric Acid Solutions by the Extract of Murraya Koenigii Leaves," Materials Chemistry and Physics, Vol. 18, No. 122, 2010, pp. 114-122. doi:10.1016/j.matchemphys.2010.02.066

[4] P. Kalaiselvi, S. Chellammal, et al., "Artemisia Pallens as Corrosion Inhibitor for Mild Steel in $\mathrm{HCl}$ Mediun," Materials Chemistry and Physics, Vol. 18, No. 120, 2010, pp. 643-648. doi:10.1016/j.matchemphys.2009.12.015

[5] A. Kumar Mishra and R. Balasubramaniam, "The Electrochemical Behaviour of Environment-Friendly Inhibitors of Silicate and Phosphonate in Corrosion Control of Carbon Steel in Soft Water Media," Materials Chemistry and Physics, Vol. 55, No. 103, 2007, pp. 385-393.

[6] P. C. Okafor, M. E. Ikp and I. E. Uwah, "Inhibitory Action of Phyllanthus Amarus Extracts on the Corrosion of Mild Steel in Acidic Media," Corrosion Science, Vol. 21, No. 50, 2008, pp. 2310-2113. doi:10.1016/j.corsci.2008.05.009
[7] C. Dominkovics and G. Harsanyi, "Fractal Description of Dendrite Growth during Electrochemical Migration," Journal of Microelectronics Reliability, Vol. 33, No. 48, 2008, pp. 1635-1630.

[8] S. A. A. EI-Maksoud, "The Effect of Organic Compounds on the Electrochemical Behaviour of Steel in Acidic Media. A review," International Journal of Electrochemistry, Vol. 18, No. 3, 2008, pp. 535-538.

[9] D. D. Macdonald, "Reflections on the History of Electrochemical Impedances Pectroscopy," Journal of Electrochimical Acta, Vol. 8, No. 51, 2006, pp. 1378-1382.

[10] Chinese Society for Corrosion and Protection Society, "Electrochemical Corrosion Research Methods," Chemical Industry Press, China, Vol. 4, No. 4, 1998, pp. 78-80.

[11] S.-Z. Zheng, "The Application Guide Recycled Cooling Water Quality and Water Treatment Standards," Chemical Industry Press of Beijing, Beijing, Vol. 12, No. 2, 2003, pp. 156-158.

[12] C. A. C. Souza, et al., "Influence of Corrosion and Partial Crystallization on Corrosion Resistance of Fe-M-B-Cu (M=Zr,Nb,Mo) Alloys," Journal of Non-Crystalline Solids, Vol. 22, No. 273, 2000, pp. 281-284.

[13] S. Mato, G. Alcata, et al., "Corrosion Behavior of a Ti-Base Nanostructure-Dendrite Composite," Journal of Electrochimical Acta, Vol. 18, No. 50, 2005, pp. 24612462. doi:10.1016/j.electacta.2004.10.071

[14] A. E. Mattel and M. Calvin, "Metal Chelate Chemistry," Science Industry Press of Beijing, Beijing, 1964, pp. 55110.

[15] J. Zhang, Z. P. Li, W. M. Zhao, W. Y. Guo and Y. Wang, "Acta Petrolei Sinica," Journal of Petroleum Processing Section, Vol. 21, No. 24, 2008, pp. 995-998. 